\title{
Temporal and spatial variability of the surface energy balance in Dronning Maud Land, East Antaretica
}

\author{
C. H. Reijmer and J. Oerlemans \\ Institute for Marine and Atmospheric Research Utrecht, Utrecht University, Utrecht, Netherlands \\ Received 30 October 2000; revised 29 January 2002; accepted 2 February 2002; published 19 December 2002.
}

[1] We present data of nine Automatic Weather Stations (AWS), which are located in Dronning Maud Land (DML), East Antarctica, since the austral summer of 1997. Potential temperature and wind speed are maximum at the sites with the steepest surface slope, i.e., at the edge of the Antarctic plateau. Specific humidity and accumulation decrease with elevation and distance from the coast. The annual average energy gain at the surface from the downward sensible heat flux varies between $\sim 3 \mathrm{~W} \mathrm{~m}^{-2}$ and $\sim 25 \mathrm{~W} \mathrm{~m}^{-2}$, with the highest values at the sites with the largest surface inclination and wind speeds. The net radiative flux is negative and largely balances this sensible heat flux and ranges from $\sim-2$ $\mathrm{W} \mathrm{m} \mathrm{m}^{-2}$ to $\sim-28 \mathrm{~W} \mathrm{~m}^{-2}$; maximum values can be linked to maxima in surface slope and wind speed, and suggest a strong connection between the heat budget and the katabatic flow in DML. The average latent heat flux is generally small and negative $\left(\sim-1 \mathrm{~W} \mathrm{~m}^{-2}\right)$ indicating a slight net mass loss through sublimation. INDEX TERMS: 1827 Hydrology: Glaciology (1863); 1863 Hydrology: Snow and ice (1827); 3307 Meteorology and Atmospheric Dynamics: Boundary layer processes; 3349 Meteorology and Atmospheric Dynamics: Polar meteorology; 9310 Information Related to Geographic Region: Antarctica; KEYWORDS: Antarctica, automatic weather stations, energy balance, Epica

Citation: Reijmer, C. H., and J. Oerlemans, Temporal and spatial variability of the surface energy balance in Dronning Maud Land, East Antarctica, J. Geophys. Res., 107(D24), 4759, doi:10.1029/2000JD000110, 2002.

\section{Introduction}

[2] Surprisingly little is known about the spatial and temporal distribution of the surface energy budget over Antarctica, although much effort has recently been put into Antarctic meteorological and glaciological research. This constitutes a significant gap in our understanding of the Antarctic climate. The surface energy balance consists of five main components and can be expressed as:

$$
S+L+H+L E+G=0,
$$

in which $S$ and $L$ are the net shortwave and net longwave radiative flux, respectively, $H$ and $L E$ are the turbulent fluxes of sensible and latent heat, respectively, and $G$ is the subsurface energy flux including surface melt. The surface energy budget governs the near surface climate and the surface mass balance through for instance the katabatic flow, which blows when the near surface air is cooled as a result of a negative net radiation balance. Energy budget studies are often incomplete since (1) they are limited to a single station [Carroll, 1982; King et al., 1996; Reijmer et al., 1999], (2) measuring periods are limited to the summer months [Ohata, 1985; Bintanja, 2000] or (3) not all relevant terms have been measured or calculated [e.g., Stearns and Weidner, 1993]. In this paper we present the complete energy balance for several locations in Dronning Maud Land (DML), East Antarctica, over a period of several years.

[3] At present, the Institute for Marine and Atmospheric Research Utrecht (IMAU) operates nine Automatic Weather Stations (AWS) in DML (Figure 1). The main objective is to extend our knowledge of the near surface climate and heat budget of Antarctica. Data from the AWS will provide insight in the meteorological conditions in DML over a period of several years. Previous annual records were presented by Jonsson [1995], König-Langlo et al. [1998] and Bintanja and Reijmer [2001]. The data may also be used to validate climate and weather prediction models that are currently used to study the Antarctic climate [Genthon and Braun, 1995; King and Connolley, 1997; Krinner et al., 1997; Van Lipzig et al., 1999].

[4] The AWS are a contribution to the European Project for Ice Coring in Antarctica (EPICA). The broad objective of EPICA is to reconstruct the Antarctic climate record with high temporal resolution. To achieve this objective, two deep ice cores will be drilled, one of which is located in DML. The purpose of the AWS within this project is to increase our knowledge of the surface mass balance in DML and to quantify the energy exchange processes between atmosphere and snow surface. Eventually, this will help with the interpretation of ice cores.

[5] In this paper we examine the spatial and temporal variability of the surface energy budget in DML. The surface energy budget is evaluated using measurements 


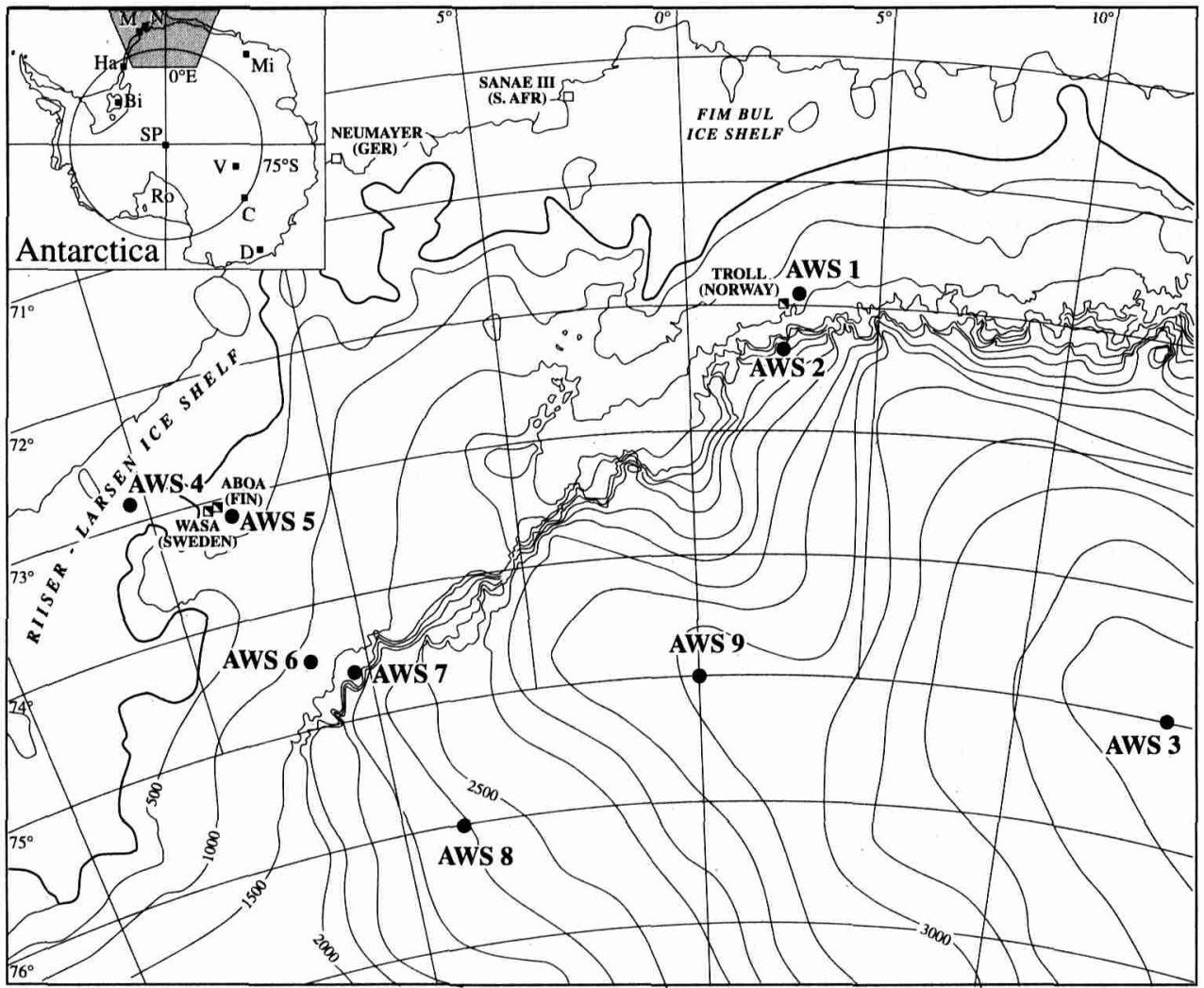

Figure 1. Map of Dronning Maud Land (DML), Antarctica, showing the locations of the Automatic Weather Stations (AWS). AWS 9 is situated $\sim 2 \mathrm{~km}$ west of the EPICA DML drilling site. In the inset map of Antarctica the shaded area represents DML and the letters denote sites mentioned in the text: $\mathrm{Bi}$, Berkner Island; Ha, Halley; M, Maudheim; N, Neumayer; Mi, Mizuho; SP, South Pole; V, Vostok; C, Dome C; D, D-47; Ro, the Ross ice shelf.

and model calculations. Section 2 describes the experimental setup and location of the weather stations followed by a general description of the prevailing meteorological conditions in DML in section 3. Section 4 gives a brief description of the energy balance model and a verification of the model. The results are described in section 5 and discussed in section 6 .

\section{Location and Experimental Setup}

[6] Figure 1 shows the locations of the AWS in DML. In January 1997, AWS 1 to 3 were installed during a Norwegian/Swedish/Dutch ground traverse [Van den Broeke et al., 1999]. In the austral summer of 1997-1998, five additional stations (AWS 4 to 8 ) were installed during a Swedish/ Norwegian/Dutch ground traverse [Holmlund et al., 2000]. Staff of the Alfred Wegener Institute in Germany established AWS 9 about $2 \mathrm{~km}$ west of the EPICA drilling site in DML, in December 1997. Table 1 provides additional information about all stations.

[7] The locations of the AWS were chosen so that a substantial part of western DML was covered and are located in very different climate regimes. AWS 4 is located in the coastal area on an ice shelf, AWS 5 on the lower part of the ice sheet near the grounding line, AWS 1, 2, 6 and 7 in the escarpment region and AWS 3, 8 and 9 on the Antarctic plateau. All these stations are located on snow; only AWS 7 is located on blue ice. Results from this station are presented by Bintanja and Reijmer [2001].

[8] Each station consists of a vertical mast placed on a four-legged frame. They carry sensors that measure air temperature, wind speed, wind direction, instrument height, air pressure and incoming shortwave radiation (Figure 2). Except AWS 2, all stations additionally measure firn temperatures at eight (AWS 1 and 3) or ten (AWS 4 to 9) depths. AWS 4 to 9 additionally measure relative humidity, reflected shortwave radiation, and incoming and outgoing longwave radiation. The stations sample every $6 \mathrm{~min}$ (AWS 1 to 3 ) or $5 \mathrm{~min}$ (AWS 4 to 9 ). Hourly means are calculated for AWS 1 to 3, and 2-hourly means for AWS 4 to 9. The (2-)hourly averages are stored locally and transmitted using Argos transmitters. The stations are powered with batteries and are designed to work for 2 to 3 years without being serviced.

[9] The accuracy of the sensors was tested in an intercomparison experiment in the Netherlands prior to their deployment in Antarctica. The radiation sensors were calibrated before and after their operation in Antarctica and exhibit an instrumental drift of $\sim 10 \%$. The resulting uncertainty in the shortwave and longwave radiative fluxes is estimated at $\sim 10 \%$ and $\sim 20 \%$, respectively. The sensors are not artificially ventilated for reasons of energy efficiency, which particularly affects the accuracy of the air temperature and relative humidity sensors. The magnitude of the 
Table 1. Characteristics of the AWS Used in this Paper ${ }^{\mathrm{a}}$

\begin{tabular}{|c|c|c|c|c|c|c|c|}
\hline $\mathrm{AWS}^{\mathrm{b}}$ & Latitude & Longitude & Elevation, $\mathrm{m}$ a.s.l. & Slope, $\mathrm{m} \mathrm{km}^{-1}$ & Start Date & $H_{\text {init }}, \mathrm{m}$ & $\rho, \mathrm{g} \mathrm{kg}^{-1}$ \\
\hline 1 (Site A) & $71^{\circ} 54.00^{\prime} \mathrm{S}$ & $3^{\circ} 05.00^{\prime} \mathrm{E}$ & 1420 & $19.5 \pm 25.1$ & $31-12-1996$ & 3.19 & $370 \pm 2$ \\
\hline 2 (Site C) & $72^{\circ} 15.07^{\prime} \mathrm{S}$ & $2^{\circ} 53.47^{\prime} \mathrm{E}$ & 2400 & $37.2 \pm 15.7$ & 03-01-1997 & 2.90 & $325 \pm 25$ \\
\hline 3 (Site M) & $74^{\circ} 59.98^{\prime} \mathrm{S}$ & $15^{\circ} 00.1^{\prime} \mathrm{E}$ & 3453 & $0.7 \pm 0.3$ & 28-01-1997 & 2.56 & $325 \pm 8$ \\
\hline $4(1090)$ & $72^{\circ} 45.16^{\prime} \mathrm{S}$ & $15^{\circ} 29.93^{\prime} \mathrm{W}$ & 34 & $0.0 \pm 0.5$ & $19-12-1997$ & 2.63 & $390 \pm 50$ \\
\hline $5(\mathrm{CM})$ & $73^{\circ} 06.32^{\prime} \mathrm{S}$ & $13^{\circ} 09.88^{\prime} \mathrm{W}$ & 363 & $13.5 \pm 6.4$ & $02-02-1998$ & 2.73 & $450 \pm 26$ \\
\hline 6 (Svea cross) & $74^{\circ} 28.89^{\prime} \mathrm{S}$ & $11^{\circ} 31.01^{\prime} \mathrm{W}$ & 1160 & $15.0 \pm 30.9$ & $14-01-1998$ & 2.83 & $450 \pm 50$ \\
\hline 7 (SBB01) & $74^{\circ} 34.67^{\prime} \mathrm{S}$ & $11^{\circ} 02.97^{\prime} \mathrm{W}$ & 1172 & - & $31-12-1997$ & 2.70 & 850 \\
\hline $8(\mathrm{CV})$ & $76^{\circ} 00.02^{\prime} \mathrm{S}$ & $8^{\circ} 03.03^{\prime} W$ & 2399 & $2.2 \pm 0.8$ & $12-01-1998$ & 2.64 & $345 \pm 22$ \\
\hline 9 (DML05) & $75^{\circ} 00.15^{\prime} \mathrm{S}$ & $0^{\circ} 00.44^{\prime} \mathrm{E}$ & 2892 & $1.3 \pm 0.3$ & $29-12-1997$ & 2.26 & $335 \pm 25$ \\
\hline
\end{tabular}

${ }^{\text {a }}$ The surface slope is based on a 10 by $10 \mathrm{~km}$ Antarctic Topography (data courtesy of J. Bamber, Bristol University, 1999). Slope error estimates are the standard deviations in the mean of eight points surrounding the AWS. AWS 7 is located in a valley, not resolved in this topography; therefore the calculated slope is uncertain and has been omitted. Variables are defined as follows: $H_{\text {init }}$, initial height of the sensors; $\rho$, mean snow density based on firn core measurements averaged over the first $0.5 \mathrm{~m}$ of firn. Density data for AWS 1, 2 and 3 courtesy of M.R. van den Broeke, 1999; AWS 4, 5 and 8 courtesy of L. Karlöf, 1999; AWS 9 courtesy of H. Oerter, 2000.

between brackets: internationally used names for the sites. References are as follows: Site A, C and M, Van den Broeke et al. [1999]; 1090, CM, Svea cross, SBB01 and CV, Holmlund et al. [2000]; DML05, Oerter et al. [2000].

error depends on the amount of reflected solar radiation, the wind speed and the type of radiation shield of the sensor. In summer, the temperature error can be as large as $10^{\circ} \mathrm{C}$ at AWS 1 to 3 . AWS 4 to 9 use different radiation shields and sensors; comparisons with ventilated temperature and humidity sensors show no significant radiation error at these stations. In temperatures below $0{ }^{\circ} \mathrm{C}$, the maximum value measured by the relative humidity sensors decreases strongly. The measurements are corrected for this effect using the method of Anderson [1994]. After correction, the uncertainty in the relative humidity is about $5 \%$. Another problem is the occasional occurrence of rime on the sensors. This causes the wind speed and wind direction sensors to jam, while it shields the instrument height and radiation sensors. Problems with data transmission occasionally resulted in gaps in the data set. AWS 3,8 and 9 stopped transmitting in winter owing to the low temperatures. AWS 3 was necessarily omitted from this analysis due to missing data. The results presented here comprise a 3-year data set for AWS 1 and 2 and a 2 -year data set for AWS 4 to 9 .

\section{Prevailing Meteorological Conditions}

[10] The climate of DML is dominated by transient cyclones traveling eastward along to the coast. The influence of these cyclones decreases towards the interior of DML, where the near-surface climate is increasingly influenced by katabatic flows [Parish and Bromwich, 1991, 1998]. The results of the energy balance calculations in the next sections are presented in terms of the geographical locations of the AWS. For the purpose of clarity, DML is subdivided into three regions: (1) the ice shelves, (2) the escarpment region and (3) the Antarctic plateau. A similar subdivision was made by Fortuin and Oerlemans [1990]. These regions are significantly different in terms of climate and topography, which results in typical characteristics with respect to mean values, long-term variations and diurnal cycle of the meteorological variables. To illustrate the average near-surface conditions in DML, Figure 3 presents monthly mean air temperature, specific humidity and wind speed, and daily mean cumulative accumulation for AWS 4, 6 and 9, which represent the ice shelf region, the escarpment region and the plateau region, respectively. Table 2 shows annual averages of temperature, wind speed and humidity for all AWS.
[11] The air temperature in DML is highly variable, especially in winter when the north-south and vertical temperature gradients are largest. Fluctuations of 20 to 30 ${ }^{\circ} \mathrm{C}$ within a few days are not uncommon and are often recorded almost simultaneously at several stations (not shown). In summer, the lowest stations (AWS 4, 5 and 6) occasionally experience temperatures above $0{ }^{\circ} \mathrm{C}$. The annual and monthly mean temperature differences between the lowest stations (AWS 1, 4, 5 and 6) are small or even reversed from what would be expected from the differences in elevation (Figure 3a, AWS 4 and 6). For example, the annual mean temperature at AWS 5 is $\sim 3{ }^{\circ} \mathrm{C}$ higher than at AWS 4 , while it is located $\sim 300 \mathrm{~m}$ higher and $\sim 100 \mathrm{~km}$ more inland. The explanation for this phenomenon is that the potential temperature $(\theta)$ actually increases with elevation and exhibits a maximum on the slope towards the plateau (Figure 4). This reversal in temperature gradient and maximum in $\theta$ can be attributed to the increase in katabatic wind speed with increasing surface slope. Stronger winds enhance vertical mixing and reduce the strength of the surface temperature inversion, which results in relatively high surface temperatures and $\theta$ [Ohata, 1985; Jonsson,

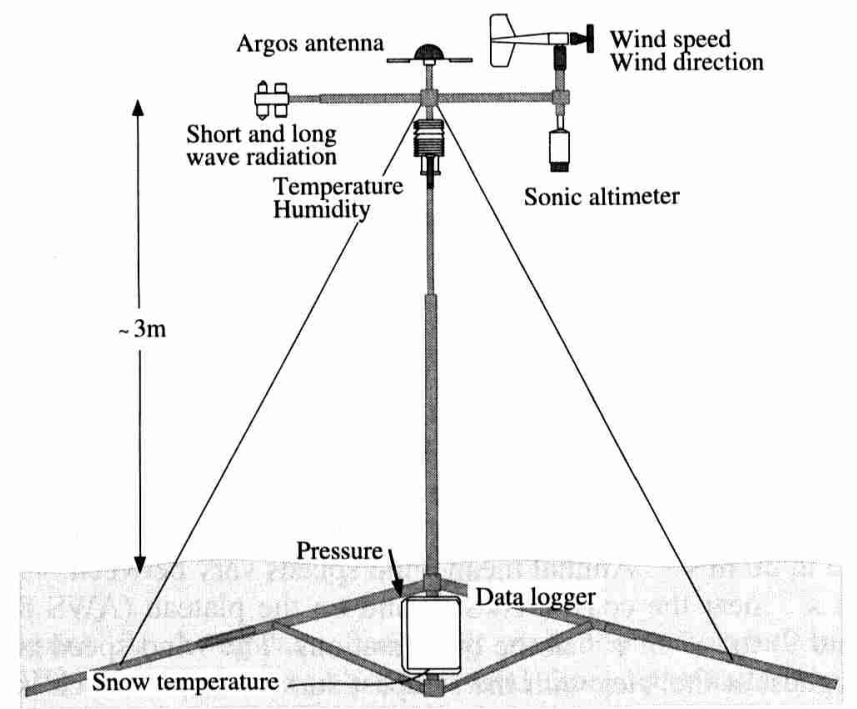

Figure 2. Schematic picture of an automatic weather station. 


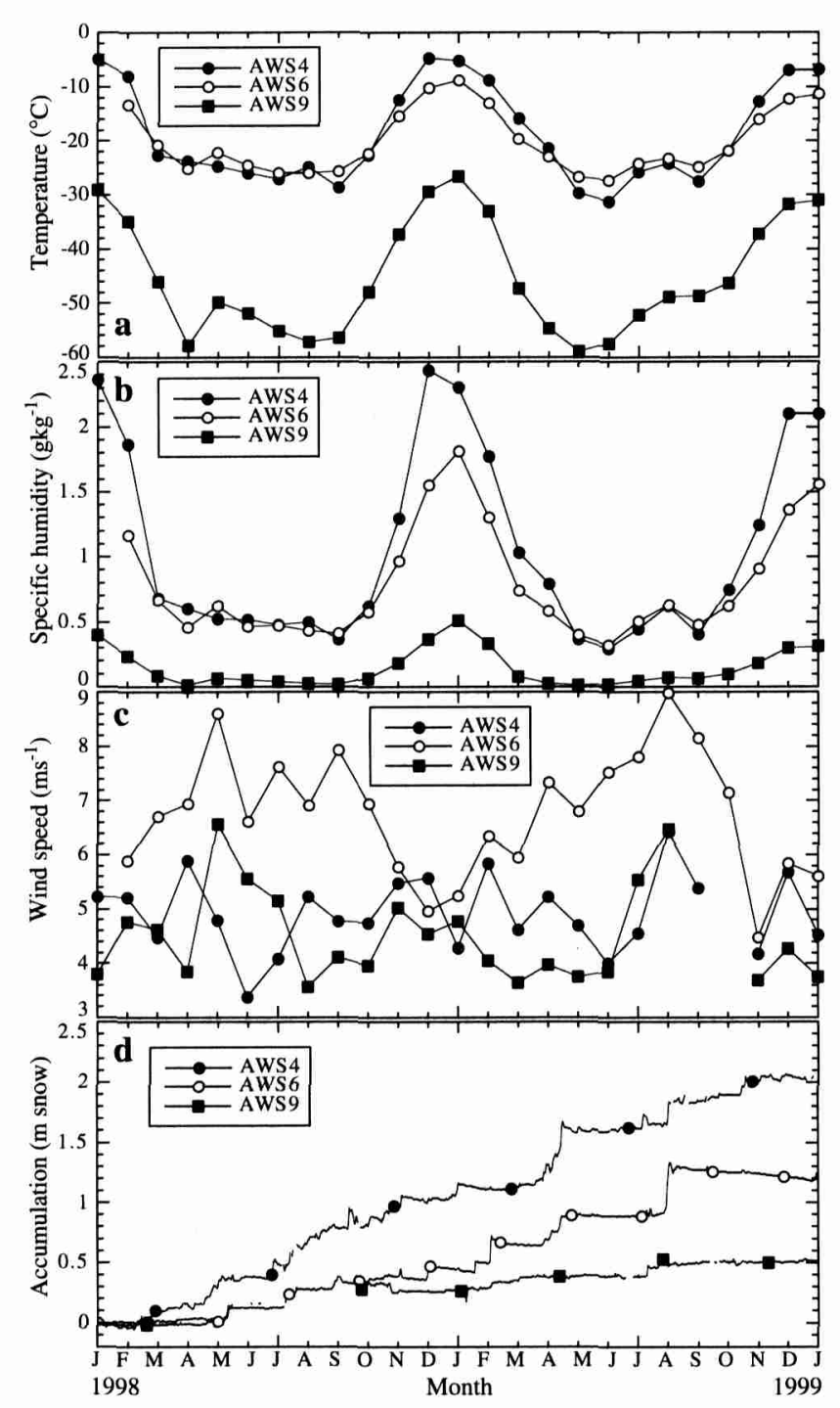

Figure 3. Monthly mean (a) air temperature, (b) specific humidity and (c) wind speed, and (d) daily mean cumulative accumulation of AWS 4 (34 m a.s.l.), 6 (1160 m a.s.l.) and 9 (2892 $\mathrm{m}$ a.s.l.) for the period January 1998 to December 1999.

1995; Van den Broeke et al., 1999]. The interannual temperature variability is small.

[12] The specific humidity is extremely low, especially in winter with values of $0.5 \mathrm{~g} \mathrm{~kg}^{-1}$ near the coast to $0.05 \mathrm{~g}$ $\mathrm{kg}^{-1}$ on the plateau. The short-term variability in relative as well as specific humidity is large and exhibits a strong correlation with temperature.

[13] A clear annual cycle in wind speed is observed at all stations except AWS 4 and 9 (Figure 3c). The wind speed is higher in winter due to the stronger katabatic and synoptic forcing. Maximum (2-)hourly mean wind speeds can reach 25 to $30 \mathrm{~m} \mathrm{~s}^{-1}$. Annual mean wind speeds vary between $\sim 5$ $\mathrm{m} \mathrm{s}^{-1}$ near the coast (AWS 4) and on the plateau (AWS 8 and 9) to $\sim 7 \mathrm{~m} \mathrm{~s}^{-1}$ at the other stations. The wind speed is highest at the sites with the steepest surface slope, which is in the escarpment region (Figure 4). This is due to the fact that the intensity of the katabatic flow is, to a first approximation, proportional to the slope angle of the underlying surface [Parish and Bromwich, 1987, 1991]. The annual mean wind speed is lower than at AWS 5 and 6 in spite of the high surface slope at AWS 1 and 2. This can partly be explained by an underestimation of the wind speed due to freezing of the sensors in winter and partly by the location of the stations with respect to the topography. Two-dimensional patterns in the terrain induce confluence and divergence of the katabatic flow which disturbs the ideal two-dimensional situation [Parish and Bromwich, 1991].

[14] Accumulation is derived from the changes in instrument height measured with a sonic altimeter and measured snow density (Table 1), and decreases with distance to the coast and with increasing elevation. Accumulation occurs mainly in a few major events per year, which contribute $\sim 80 \%$ to the annual accumulation (Figure $3 \mathrm{~d}$ ). The interannual variability is large, especially at the high accumulation sites close to the coast. The determined accumulation is higher than the mean values derived from shallow firn core studies. Isaksson and Karlén [1994] present an averaged value (1976-1989) of $415 \mathrm{~mm}$ water equivalent per year (w.e. $\mathrm{yr}^{-1}$ ) near the coast (near AWS 4) and Karlöf et al. [2000] and Oerter et al. [2000] present average values of 68 (1965-1997) and $62 \mathrm{~mm}$ w.e. $\mathrm{yr}^{-1}(1801-1897)$ at the plateau near AWS 8 and 9, respectively.

\section{Model Description and Validation}

[15] The surface energy fluxes presented in section 5 are based partly on measurements and partly on model calculations. The model we use to calculate the turbulent fluxes and the subsurface temperatures is extensively described by Greuell and Konzelman [1994] and by Reijmer et al. [1999]. Here, we give a brief description.

[16] Equation (1) presents the surface energy balance. Fluxes towards the surface are taken to be positive. $S$ can be expressed as $(1-\alpha) S_{g}$ where $\alpha$ is the surface albedo and $S_{g}$ the global radiation at the surface. $S_{g}$ and $\alpha$ are derived from measurements or, when measurements are not available, $\alpha$ is taken constant (AWS 1 and 2, $\alpha=0.82$, the average of $\alpha$ at AWS 5 to 9 ). $L$ equals the incoming minus the emitted longwave flux $(L \downarrow-L \uparrow) . L \downarrow$ is either measured directly (AWS 4 to 9) or parameterized in terms of screen-level (2 m) temperature ( $T_{a}$, in K) (AWS 1, 2 and 8 ):

$$
L \downarrow=27.17+3.3616 * 10^{-8} T_{a}^{4} .
$$

This parameterization is based on 2-hourly mean measurements of $L \downarrow$ and $T_{a}$ at AWS 6 and 9. No dependency on humidity or cloud cover is included because the stations do not measure these variables. Since $L \downarrow$ is strongly dependent on humidity and cloud cover, this introduces a significant error in the calculated $L \downarrow$. Figure 5 illustrates the performance of equation (2) and a parameterization presented by King [1996, equation (4)]. The annual variations in $L \downarrow$ follow mainly the annual temperature wave. The annual mean $L \downarrow$ is underestimated by $\sim 8 \%$ when using equation (2) and overestimated by $\sim 8 \%$ when using the equation of King [1996]. The short-term variability is determined mainly by variations in cloud cover. Both parameterizations underestimate this variability. Equation (2) explains $\sim 34 \%$ of the total variance and equation (4) of King [1996] explains $\sim 19 \%$. $L \uparrow$ is calculated using the 
Table 2. Annual Averages of the Meteorological Data (see Table 1) ${ }^{\mathrm{a}}$

\begin{tabular}{|c|c|c|c|c|c|c|c|c|}
\hline AWS & $\mathrm{yr}$ & $T,{ }^{\circ} \mathrm{C}$ & $\theta, \mathbf{K}$ & $R H, \%$ & $q, \mathrm{~g} \mathrm{~kg}^{-1}$ & $W S, \mathrm{~m} \mathrm{~s}^{-1}$ & $\alpha$ & acc., $\mathrm{mm}$ w.e. $\mathrm{yr}^{-1}$ \\
\hline \multirow[t]{2}{*}{$1(1420)$} & 1997 & -21.5 & 269.0 & - & - & 6.8 & - & $211 \pm 8$ \\
\hline & 1998 & -22.7 & 268.0 & - & - & 6.1 & - & $130 \pm 8$ \\
\hline \multirow{3}{*}{$2(2400)$} & 1999 & - & - & - & - & 6.2 & - & $133 \pm 8$ \\
\hline & 1997 & -26.3 & 273.0 & - & - & 6.7 & - & $111 \pm 21$ \\
\hline & 1998 & -27.9 & 271.7 & - & - & 6.3 & - & $88 \pm 15$ \\
\hline \multirow{3}{*}{$4(34)$} & 1999 & -27.6 & 271.9 & - & - & 6.7 & - & $13 \pm 15$ \\
\hline & 1998 & -19.2 & 255.8 & 76.6 & 1.02 & 4.9 & 0.86 & $452 \pm 61$ \\
\hline & 1999 & -19.3 & 255.5 & 77.2 & 1.01 & 5.0 & 0.88 & $371 \pm 51$ \\
\hline $5(363)$ & 1998 & -16.4 & 261.4 & 70.8 & 1.02 & 6.6 & 0.83 & $144 \pm 28$ \\
\hline \multirow{2}{*}{$6(1160)$} & 1999 & -16.4 & 261.3 & 71.1 & 1.01 & 6.4 & 0.84 & $270 \pm 27$ \\
\hline & 1998 & -20.1 & 264.9 & 67.1 & 0.77 & 6.6 & 0.81 & $207 \pm 23$ \\
\hline \multirow{2}{*}{8 (2399) } & 1999 & -20.1 & 264.7 & 68.9 & 0.80 & 6.8 & 0.83 & $333 \pm 38$ \\
\hline & 1998 & -38.3 & 258.4 & 63.9 & 0.23 & 5.4 & 0.78 & $90 \pm 7$ \\
\hline \multirow{3}{*}{9 (2892) } & 1999 & -37.7 & 258.9 & 64.0 & 0.25 & 5.2 & 0.80 & $62 \pm 5$ \\
\hline & 1998 & -46.1 & 254.4 & 58.5 & 0.13 & 4.6 & 0.83 & $91 \pm 8$ \\
\hline & 1999 & -45.3 & 255.1 & 59.5 & 0.14 & 4.7 & 0.84 & $84 \pm 7$ \\
\hline
\end{tabular}

${ }^{\text {a }}$ The averages are based on (two-)hourly values. To obtain averages over a complete year, missing days in January 1997 (AWS 2) and January 1998 (AWS 5, 6 and 8) are replaced with corresponding days of January 1998 and 1999, respectively. Between brackets: the elevation of the stations in m a.s.1.; dashes indicate lack of data. Variables are defined as follows: $T$, temperature; $\theta$, potential temperature; $R H$, relative humidity; $q$, specific humidity; $W S$, wind speed; $\alpha$, albedo; acc., accumulation based on sensor height measurements and measured snow density (Table 1).

Stefan-Boltzmann law for black body radiation, $L \uparrow=\sigma T_{0}^{4}$ with surface temperature $T_{0}$, Stefan-Boltzmann constant $\sigma$ and a surface emissivity of 1 .

[17] The surface temperature $T_{0}$ is calculated using a firn model. In the firn model the subsurface temperatures are calculated on a vertical grid extending $25 \mathrm{~m}$ into the firn. This model includes shortwave radiation penetration, melting, refreezing and densification of the snow pack. The surface temperature is a linear extrapolation of the firn temperature of the upper two grid layers. The initial profiles of temperature are based on snow temperature measurements, while the initial profiles of density are based on firn core measurements (date courtesy of M.R. van den Broeke, 1999, L. Karlöf, 1999, and H. Oerter, 2000).

[18] The turbulent fluxes are calculated from the vertical gradients in wind speed, temperature and specific humidity between sensor height and surface using Monin-Obukhov similarity theory. In unstable conditions the stability functions presented by Högström [1988] are used, while in stable conditions we use the functions of Duynkerke [1991]. The surface roughness length of momentum is assumed to be $0.1 \mathrm{~mm}$ [King and Turner, 1997], while the surface roughness lengths of heat and moisture are calculated according to the theory of Andreas [1987]. For this purpose surface temperatures are taken from the firn
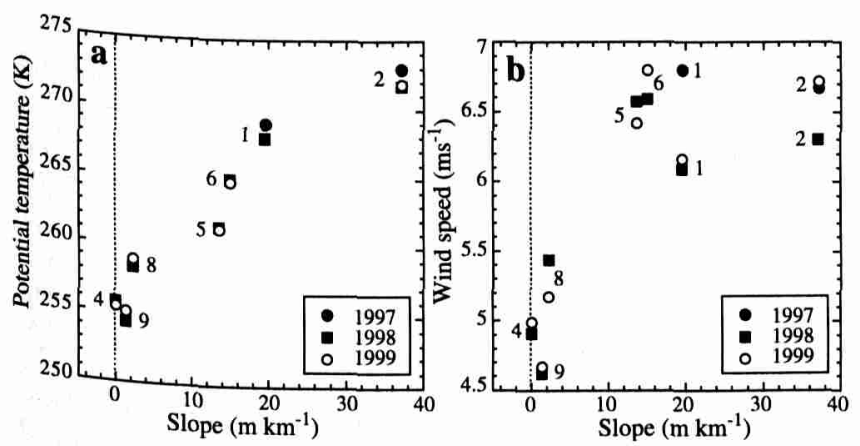

Figure 4. Annual mean (a) potential temperature and (b) wind speed as a function of surface slope. The numbers denote AWS sites. model, while the specific humidity at the surface equals the ice-saturation value for $T_{0}$. The screen-level temperatures and specific humidity's are corrected for temporal changes in measurement height due to accumulation. For AWS 1 and 2 the relative humidity $(R H)$ was not measured but taken constant $(R H=65 \%$, which is $\sim 2 \%$ lower than the average $R H$ measured at AWS 6 and 8, which are at slightly lower elevation than AWS 1 and 2). The subsurface energy flux is the residual of all other terms and is subdivided into a conductive heat flux, a penetrating part of the shortwave radiative flux, melting and refreezing.

[19] The only measurements available to compare with model output, are $L \uparrow$ and the snow temperatures. The model is fine-tuned by minimizing the difference in simulated and measured $L \uparrow$ or when this is not available by minimizing the temperature difference between simulated and measured snow temperature of the highest snow sensor using the shortwave radiation extinction coefficients of snow. This method can be used for all sites except AWS 2 where we use the values determined for AWS 1 . The energy balance presented in sections 5 and 6 are based on the results after fine-tuning.

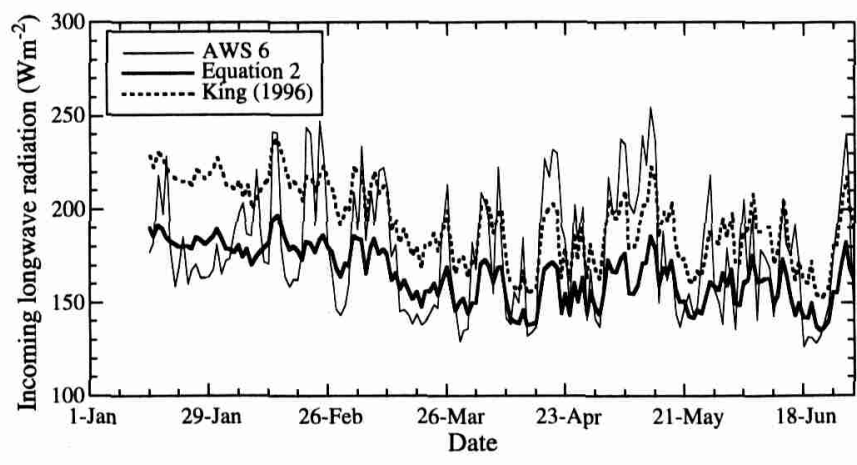

Figure 5. Longwave incoming radiation measured at AWS 6 (1160 m a.s.l.) (thin solid line), parameterized using equation (2) (thick solid line) and parameterized using equation (4) of King et al. [1996] (dashed line), for the period 14 January to 30 June 1998. 


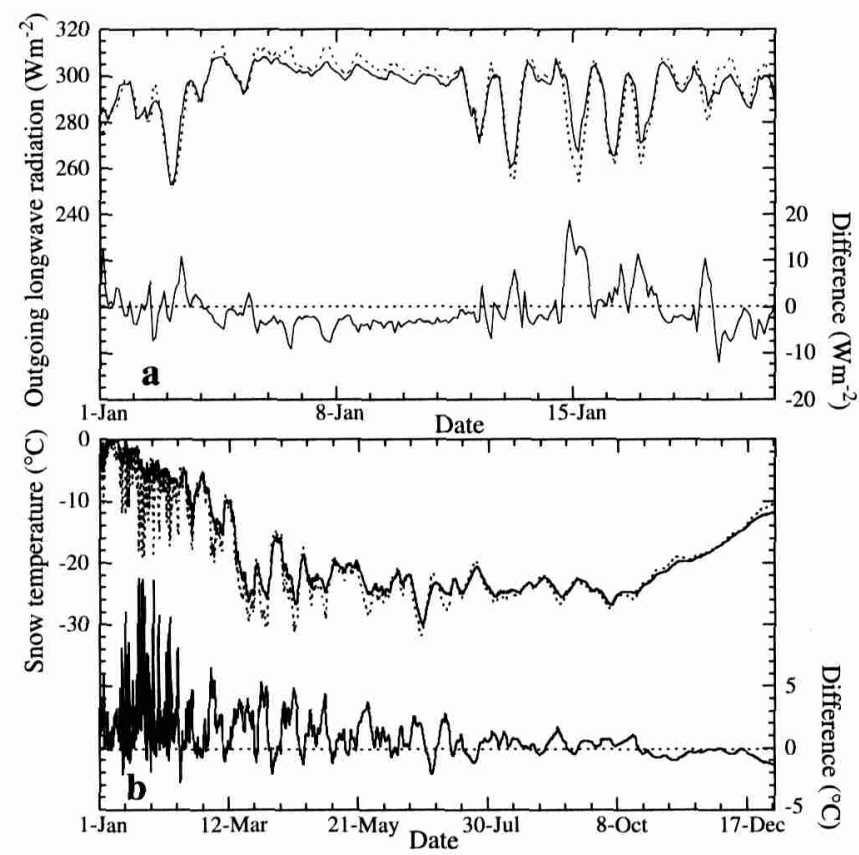

Figure 6. Measured (solid line) and simulated (dotted line), and the difference (measured minus simulated) of (a) outgoing longwave radiation for January 1998 and (b) snow temperature at initial dept of $0.05 \mathrm{~m}$ for 1998, for AWS 4 (34 $\mathrm{m}$ a.s.l.).

[20] Figure 6a presents the simulated and measured $L \uparrow$ and the difference between the two for AWS 4 after tuning. During the short peaked summer, $L \uparrow$ is over-estimated whereas it is too low in winter. On average, simulated $L \uparrow$ is under-estimated (Table 3), which implies that the mean simulated surface temperature is also underestimated (by $\sim 0.4{ }^{\circ} \mathrm{C}$ at AWS 4,5 and $6, \sim 1.6{ }^{\circ} \mathrm{C}$ at AWS 8 and $\sim 3.8$ ${ }^{\circ} \mathrm{C}$ at AWS 9). Other stations show similar results. In winter, AWS 8 and 9 have problems measuring $L \uparrow$ due to the low temperatures. This could explain part of the larger differences

Table 3. Quantities Related to the Differences in Simulated and Measured $L \uparrow$ and $T_{s n}{ }^{a}$

\begin{tabular}{lcccc}
\hline & $\mathrm{D}_{\text {mean }}$ & $\mathrm{D}_{\min }$ & $\mathrm{D}_{\max }$ & $\sigma_{\text {diff }}$ \\
\hline & \multicolumn{4}{c}{$L \uparrow, \mathrm{W}, \mathrm{m}^{-2}$} \\
AWS 4 & 1.7 & -25.7 & 34.6 & 4.9 \\
AWS 5 & 1.4 & -60.1 & 35.7 & 5.4 \\
AWS 6 & 2.6 & -18.8 & 38.5 & 4.8 \\
AWS 8 & 5.4 & -28.2 & 65.1 & 11.8 \\
AWS 9 & 10.7 & -31.1 & 54.9 & 6.6 \\
& & & & \\
AWS 1 & -0.16 & $T_{s n},{ }^{\circ} \mathrm{C}$ & & \\
AWS 4 & 0.51 & -6.2 & 11.3 & 1.7 \\
AWS 5 & 0.67 & -2.8 & 13.7 & 1.5 \\
AWS 6 & 0.24 & -7.2 & 10.1 & 1.7 \\
AWS 8 & 0.72 & -4.6 & 5.2 & 0.8 \\
AWS 9 & 0.66 & -6.4 & 13.0 & 2.3 \\
\hline
\end{tabular}

${ }^{a}$ The averages are based on (2-)hourly values over the period $1997-$ 1998 for AWS 1 and 1998-1999 for AWS 4 to 9. At the temperatures prevailing at AWS 4 to $9,1 \mathrm{~W} \mathrm{~m}^{-2}$ change in $L \uparrow$ represents $\sim 0.27$ to $0.35^{\circ} \mathrm{C}$ temperature change. Variables are defined as follows: $L \uparrow$, outgoing longwave radiation; $T_{s n}$, snow temperature at initial depth of $0.05 \mathrm{~m} ; \mathrm{D}_{\text {mean }}$, mean absolute difference (measured minus simulated); $D_{\text {min }}$, minimum difference; $\mathrm{D}_{\max }$ maximum difference; $\sigma_{\text {diff }}$ standard deviation of the difference. between measured and simulated $L \uparrow$ at these sites. At all sites, the average difference is smaller than the estimated uncertainty of $20 \mathrm{~W} \mathrm{~m}^{-2}$ in the longwave radiation measurements. The extreme values, however, are larger than $20 \mathrm{~W} \mathrm{~m}^{-2}$ and represent surface temperature differences of up to $20^{\circ} \mathrm{C}$.

[21] Figure $6 \mathrm{~b}$ presents the measured and simulated snow temperature $\left(T_{s n}\right)$ at an initial depth of $0.05 \mathrm{~m}$ and the temperature difference, for AWS 4. Note that the depth of the snow temperature sensors slowly increased due to accumulation. In the first summer, when the sensor is still fairly close to the surface, $T_{s n}$ is quite variable which induces large variations in the difference. When snow depth increases, the variability on time scales of days decreases and differences in simulated and measured $T_{s n}$ become smaller. The amplitude of the simulated annual $T_{s n}$ cycle is too small, the average $T_{s n}$ is too high and the snow pack slowly warms at all stations (Table 3).

[22] AWS 6 is located at the same location as site 3 of Bintanja [2000]. Bintanja [2000] presents the energy balance over the austral summer of 1997-1998, which has an overlap of about 20 days with our data. He uses direct turbulence measurements with a sonic anemometer and a Lyman- $\alpha$ hygrometer to validate the turbulent fluxes. The results of our model can be verified independently by comparing the results of AWS 6 with results of his site 3 . The temporal variations appear to agree reasonably well (not shown). $H$ is $\sim 3.6 \mathrm{~W} \mathrm{~m}^{-2}$ and $L E$ is $\sim 4.1 \mathrm{~W} \mathrm{~m}^{-2}$ higher at AWS 6 compared to site 3 , averaged over the 20-day period. The differences in $H$ and $L E$ can partly be explained by the different methods used to determine the fluxes.

[23] The sensitivity of the calculated heat budget was tested by varying the various model parameters (Table 4). The results suggest that the subsurface temperatures are particularly sensitive to changes in the amount of shortwave radiation penetrating the snow pack, i.e., sensitive to $\alpha$, snow density, shortwave radiation penetration coefficients. Fortunately, $\alpha$ and snow density were measured at most of the AWS sites. In contrast, the shortwave radiation penetration coefficients are not well known and depend on the wavelength of the radiation. Fortunately, changes in these coefficients only have a minor effect on the surface temperature and thereby the turbulent fluxes (Table 4). The turbulent fluxes are more sensitive to changes in for instance the roughness length of momentum $\left(z_{0}\right)$ and the way $L \downarrow$ is parameterized. Besides its direct effect, a change in $z_{0}$ affects $H$ and $L E$ through a change in surface roughness lengths of heat and moisture [Andreas, 1987] and a

Table 4. Sensitivity of the Calculated Surface Temperature and Turbulent Fluxes to Changes in Model Parameters ${ }^{a}$

\begin{tabular}{llcccc}
\hline \multicolumn{1}{c}{ Reference } & \multicolumn{1}{c}{ Test } & $\mathrm{d} T_{0}$ & $\mathrm{~d} T_{s n}$ & $\mathrm{~d} H$ & $\mathrm{~d} L E$ \\
\hline$\alpha=0.85$ & 0.82 & -0.2 & -0.2 & 0.7 & 0.2 \\
$\rho=350 \mathrm{~kg} \mathrm{~m}^{-3}$ & $300 \mathrm{~kg} \mathrm{~m}^{-3}$ & 0.0 & -0.4 & 0.0 & 0.0 \\
$\beta=20 \mathrm{~m}^{-1}$ & $10 \mathrm{~m}^{-1}$ & 0.0 & -0.1 & 0.0 & 0.0 \\
$\zeta=0.75$ & 0.30 & 0.0 & -0.2 & 0.0 & 0.0 \\
$z_{0}=0.1 \mathrm{~mm}$ & $1.0 \mathrm{~mm}$ & 0.4 & 0.3 & -0.7 & 0.3 \\
$L \downarrow=$ meas. & Equation (2) & 0.9 & 0.9 & -8.4 & -2.2 \\
\hline
\end{tabular}

${ }^{\text {a }}$ Differences are reference minus test. Variables are defined as follows: $T_{0}$, surface temperature in ${ }^{\circ} \mathrm{C} ; T_{s n}$, snow temperature in ${ }^{\circ} \mathrm{C}$ at initial depth of $0.05 \mathrm{~m} ; H$, sensible heat flux in $\mathrm{W} \mathrm{m}^{-2} ; L E$, latent heat flux in $\mathrm{W} \mathrm{m}^{-2} ; \alpha$, albedo; $\rho$, snow density; $\beta$, extinction coefficient snow; $\zeta$, fractional extinction coefficient; $z_{0}$, surface roughness length; $L \downarrow$, longwave incoming radiation in $\mathrm{W} \mathrm{m}^{-2}$. 
Table 5. Annual Mean Energy Balances (See Table 1) ${ }^{\mathrm{a}}$

\begin{tabular}{lccccccccccc}
\hline AWS & $\mathrm{yr}$ & $S \downarrow$ & $S \uparrow$ & $S$ & $L \downarrow$ & $L \uparrow$ & $L$ & $R$ & $H$ & $L E$ & $G$ \\
\hline $1(1420)$ & 1997 & 139.2 & -114.2 & 25.0 & 163.0 & -215.2 & -52.2 & -27.2 & 27.1 & 0.0 & 0.1 \\
& 1998 & 143.0 & -117.3 & 25.7 & 160.3 & -210.6 & -50.3 & -24.6 & 24.5 & 0.1 & 0.0 \\
\multirow{2}{*}{$(2400)$} & 1999 & - & - & - & - & - & - & - & - & - & - \\
& 1997 & 154.8 & -126.9 & 27.9 & 152.4 & -200.0 & -47.6 & -19.7 & 20.7 & -0.5 & -0.5 \\
& 1998 & 156.0 & -127.9 & 28.1 & 149.3 & -195.2 & -45.9 & -17.8 & 18.4 & -0.5 & -0.1 \\
$4(34)$ & 1999 & 151.5 & -124.2 & 27.3 & 149.8 & -196.0 & -46.2 & -18.9 & 19.9 & -0.3 & -0.7 \\
& 1998 & 117.5 & -101.0 & 16.5 & 218.4 & -236.8 & -18.4 & -1.9 & 2.9 & -0.8 & -0.2 \\
$5(363)$ & 1999 & 113.4 & -98.4 & 15.0 & 220.5 & -236.5 & -16.0 & -1.0 & 1.7 & -0.8 & 0.1 \\
& 1998 & 117.1 & -96.6 & 20.5 & 203.9 & -239.9 & -36.0 & -15.5 & 17.5 & -1.5 & -0.5 \\
$6(1160)$ & 1999 & 115.4 & -95.5 & 19.9 & 206.5 & -240.5 & -34.0 & -14.1 & 16.1 & -1.5 & -0.5 \\
& 1998 & 127.0 & -103.9 & 23.1 & 178.7 & -223.2 & -44.5 & -21.4 & 22.3 & -0.2 & -0.7 \\
$8(2399)$ & 1999 & 125.7 & -103.6 & 22.1 & 180.9 & -223.4 & -42.5 & -20.4 & 20.8 & 0.1 & -0.5 \\
& 1998 & 140.0 & -111.8 & 28.2 & 137.9 & -171.4 & -33.5 & -5.3 & 6.2 & -1.0 & 0.1 \\
$9(2892)$ & 1999 & 130.9 & -104.6 & 26.3 & 139.1 & -171.4 & -32.3 & -6.0 & 7.0 & -0.8 & -0.2 \\
& 1998 & 141.5 & -117.3 & 24.2 & 126.6 & -152.4 & -25.8 & -1.6 & 2.3 & -0.7 & 0.0 \\
& 1999 & 137.5 & -114.4 & 23.1 & 130.4 & -154.6 & -24.2 & -1.1 & 2.0 & -0.7 & -0.2 \\
\hline
\end{tabular}

${ }^{\mathrm{a}}$ The fluxes are in $\mathrm{W} \mathrm{m}^{-2}$, based on hourly means and positive directed towards the surface. To obtain averages over a complete year, missing days in January 1997 (AWS 2) and January 1998 (AWS 5, 6 and 8) were assigned values corresponding to similar days in January 1998 and 1999 , respectively. Between brackets: the elevation of the stations in $\mathrm{m}$ a.s.l.; dashes indicate lack of data. Variables are defined as follows: $S \downarrow$, incoming shortwave radiation; $S \uparrow$, reflected shortwave radiation; $S$, net shortwave radiation $(S \downarrow-S \uparrow) ; L \downarrow$, incoming longwave radiation; $L \uparrow$, outgoing longwave radiation; $L$, net longwave radiation $(L \downarrow-L \uparrow) ; R$, net radiation $(S+L) ; H$, sensible heat flux; $L E$, latent heat flux; $G$, subsurface energy flux.

change in the friction velocity. Measurements of $z_{0}$ on Antarctic snow vary between $\sim 0.5 \mathrm{~mm}$ and $\sim 1.0 \mathrm{~mm}$ [King and Turner, 1997]. Snowdrift also influences the effective $z_{0}$ because of the surface particle friction [Bintanja and Reijmer, 2001] but this is not included in the model. $H$ and $L E$ are very sensitive to changes in $L \downarrow$. Using equation 2 for $L \downarrow$ instead of measurements decreases the surface temperature by $\sim 0.9{ }^{\circ} \mathrm{C}$, increases $H$ by $\sim 8.4 \mathrm{~W} \mathrm{~m}^{-2}$ and $L E$ by $\sim 2.2 \mathrm{~W} \mathrm{~m}^{-2}$. These results are in qualitative accordance with sensitivity experiments performed with similar models [Reijmer et al., 1999; Bintanja, 2000].

\section{Results}

\subsection{Annual Mean Surface Energy Balance}

[24] The surface energy balance was calculated for all AWS except 3 and 7, over the periods 1997-1999 (AWS 1 and 2) and 1998-1999 (AWS 4 to 9). Table 5 presents the annual average energy balance for these stations.

[25] The annual averaged energy balance on Antarctica is dominated by a negative radiative flux $R(S+L)$. $R$ is determined mainly by the net longwave radiation $L$ which varies between -16 and $-52 \mathrm{~W} \mathrm{~m}^{-2} . S$ varies between 15 and $28 \mathrm{~W} \mathrm{~m}^{-2}$. $R$ is almost entirely balanced by a positive sensible heat flux $H$, ranging from $2 \mathrm{~W} \mathrm{~m}^{-2}$ at AWS 4 to 28 $\mathrm{W} \mathrm{m}^{-2}$ at AWS 1 . Positive $H$ indicates that the near-surface atmosphere is on average stably stratified and that the nearsurface air is cooled. This is the main forcing of the persistent katabatic winds on Antarctica. The low moisture content of the air results in small and negative latent heat fluxes $L E$ at almost all stations, varying between $-1.5 \mathrm{~W}$ $\mathrm{m}^{-2}$ at AWS 5 and $0.1 \mathrm{~W} \mathrm{~m}^{-2}$ at AWS 6. A negative $L E$ of $\sim-1 \mathrm{~W} \mathrm{~m}^{-2}$ implies $\sim 11 \mathrm{~mm}$ w.e. $\mathrm{yr}^{-1}$ sublimation of the Snow surface, $\sim 0$ to $10 \%$ of the annual accumulation per site. The subsurface energy flux $G$ is also small; its sign varies from year to year.

\subsection{Seasonal Cycle}

[26] Figure 7 shows the monthly mean surface heat budget of AWS 4, 6 and 9 representing the ice shelves, the escarpment region and the plateau region, respectively.
Because of the low temperatures on the Antarctic continent melt occurs rarely which means the snow is generally dry and $\alpha$ high, $0.80-0.85$ (Table 2). $S$, albeit small, dominates the radiation budget in summer, which results in positive values of $R$ (Figure 7a). In winter, in the absence of solar radiation, $L$ determines the radiative budget and $R$ is negative. The amount of time $R$ is positive in summer increases with distance to the coast, disregarding AWS 4 where $R$ is $\sim 0 \mathrm{~W} \mathrm{~m}^{-2}$ during the entire year. At AWS $1, R$ remains negative, also during summer, which is unusual for summer conditions. Bintanja [2000] also found negative $R$

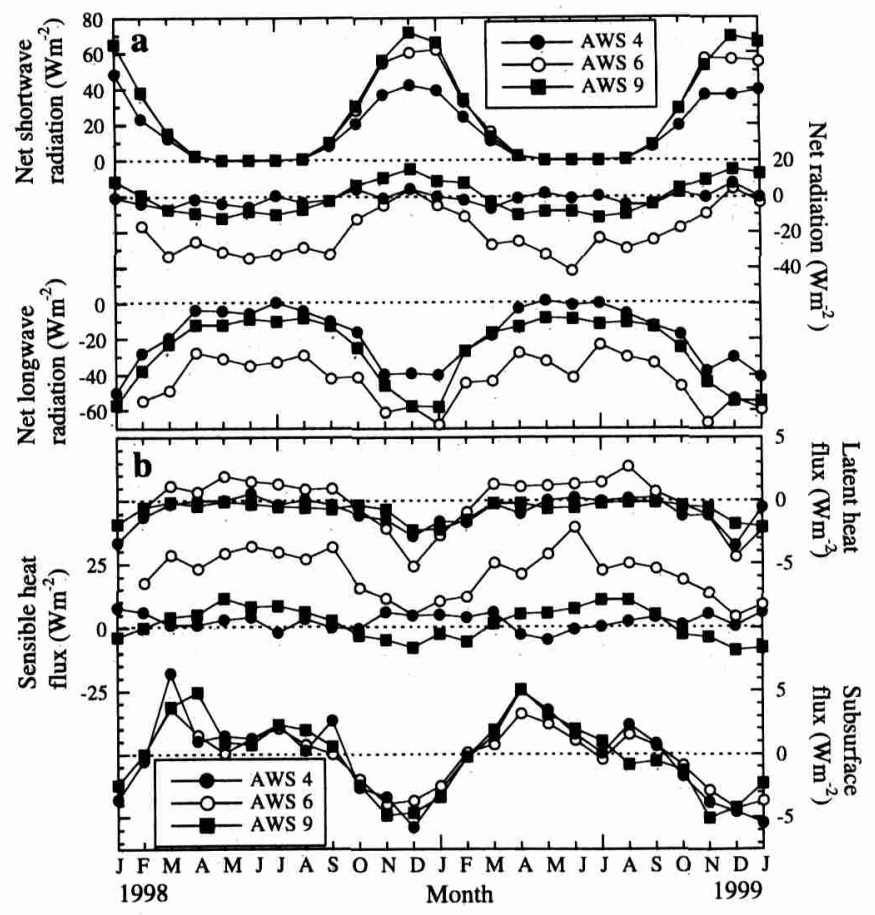

Figure 7. Monthly mean energy balance for AWS 4 (34 m a.s.1.), AWS 6 (1160 m a.s.1.) and AWS 9 (2892 m a.s.l.) for 1998 and 1999. (a) Radiative fluxes and (b) turbulent and subsurface fluxes. Dotted lines indicate $0 \mathrm{~W} \mathrm{~m}^{-2}$. 


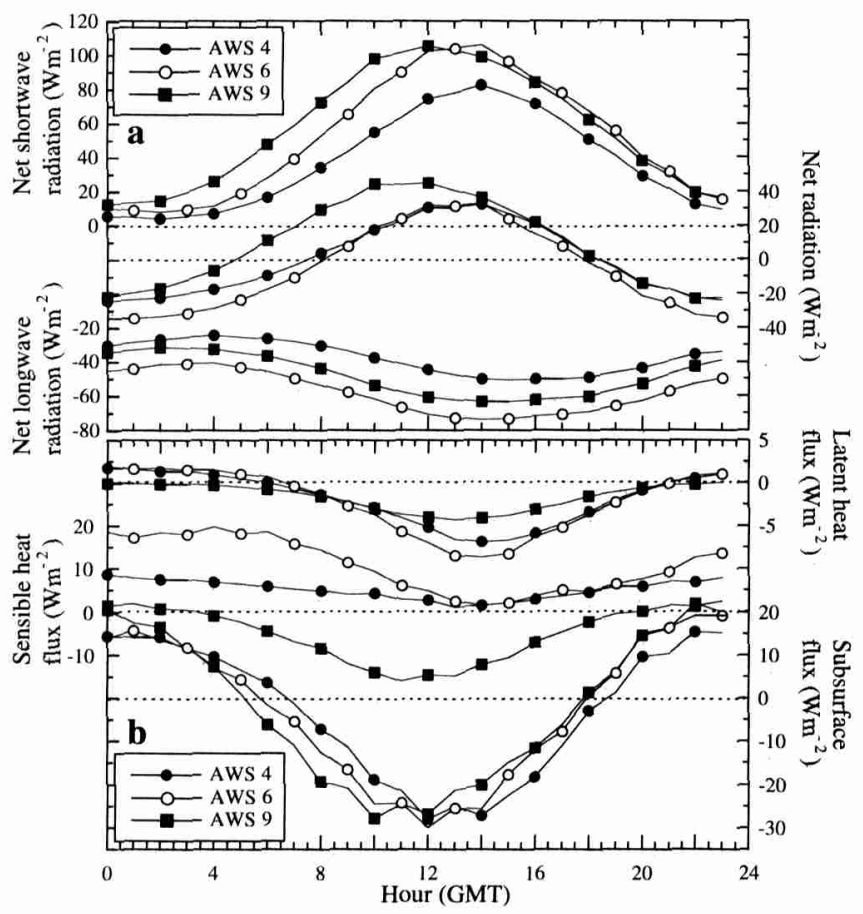

Figure 8. Diurnal cycle of the surface energy budget in summer (December, January, February) for AWS $4(34 \mathrm{~m}$ a.s.l.), AWS 6 (1160 m a.s.l.) and AWS 9 (2892 m a.s.l.). (a) Radiative fluxes and (b) turbulent and subsurface fluxes. Dotted lines indicate $0 \mathrm{~W} \mathrm{~m}^{-2}$.

in summer for three sites in the escarpment region. This phenomenon will be discussed more extensively in section 6. At AWS 5 and $6, R$ is positive in December and at AWS $2, R$ is positive from November to January. At the highest sites, $R$ is positive from October to February.

[27] $R$ is balanced largely by $H$, which is therefore positive in winter and negative in summer, especially at the higher stations, AWS 2, 8 and 9 (Figure 7b). At AWS 1, 5, and 6, $H$ becomes very small in summer but remains positive. This indicates that, on average, stable or near-neutral conditions in the surface layer persist. Unstable conditions in the surface layer in summer at the higher stations can be attributed to lower wind speeds and a more intense warming of the surface by the sun due to lower cloud amounts at larger distance from the coast. $L E$ is very small and positive (condensation) in winter and negative (sublimation) in the short summer. $G$ is small all year round, varying between -5 and $5 \mathrm{~W} \mathrm{~m}^{-2}$, and shows warming of the snow pack in summer and cooling in winter. In summer, surface temperatures occasionally can reach $0{ }^{\circ} \mathrm{C}$ for 1 or 2 hours at AWS 4, 5 and 6 and surface melt occurs. The melt water does not runoff but percolates into deeper layers and refreezes, forming ice lenses. These were observed in snow pits near AWS 4.

\subsection{Daily Cycle}

[28] The diurnal cycle in the surface energy budget is due mainly to changes in insolation and is therefore most pronounced in summer. $S$ heats the surface and destroys (in part) the surface temperature inversion, weakening the katabatic flow. Figure 8 depicts the diurnal cycle of the heat budget in summer (December, January and February) at AWS 4, 6 and
9. The diurnal cycle in $S$ is much larger than in $L: 80-110 \mathrm{~W}$ $\mathrm{m}^{-2}$ and $25-35 \mathrm{~W} \mathrm{~m}^{-2}$, respectively. This results in $R$ being dominated by $S$. $R$ is positive in daytime for $\sim 10$ hours at the lower sites (AWS 1 to 6 ) to $\sim 13$ hours at the plateau sites (AWS 8 and 9). The diurnal cycle in $L \downarrow$ is small, so the diurnal cycle in $L$ is caused mainly by variations in $L \uparrow$. Therefore, energy losses due to $L$ are largest when the surface temperature is highest, which is about an hour after solar noon. The phase difference between the stations is due to differences in their longitudinal location.

[29] $H$ is determined mainly by the temperature difference between air and surface, and wind speed. During daytime the conditions are neutral or only marginally unstable at the lower sites (AWS 1, 4, 5 and 6), whereas unstable conditions prevail at the higher sites (AWS 2, 8 and 9), causing warming of the lower boundary layer (Figure 8b). During the night, $H$ is positive and largest for the stations with the highest wind speed. $L E$ is small at all stations and shows condensation at night and sublimation during the day. $G$ shows a marked diurnal cycle that is closely related to the solar heating of the snow pack.

\section{Discussion}

\subsection{Surface Energy Balance}

[30] The results presented in the previous sections suggest that the katabatic flow is of great importance for the
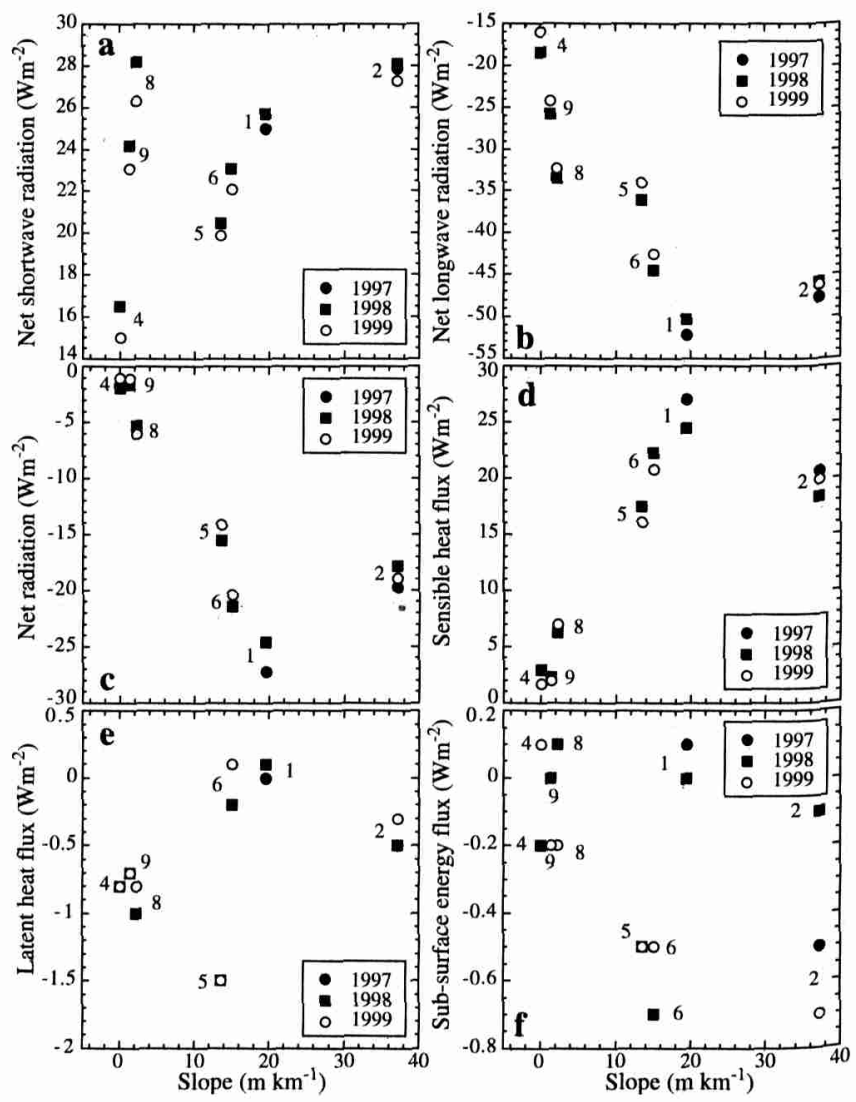

Figure 9. Annually averaged surface fluxes terms, (a) net shortwave radiation, (b) net longwave radiation, (c) net radiation, (d) sensible heat flux, (e) latent heat flux and (f) subsurface energy flux, as a function of surface slope (Table 1). The numbers denote the AWS sites. 

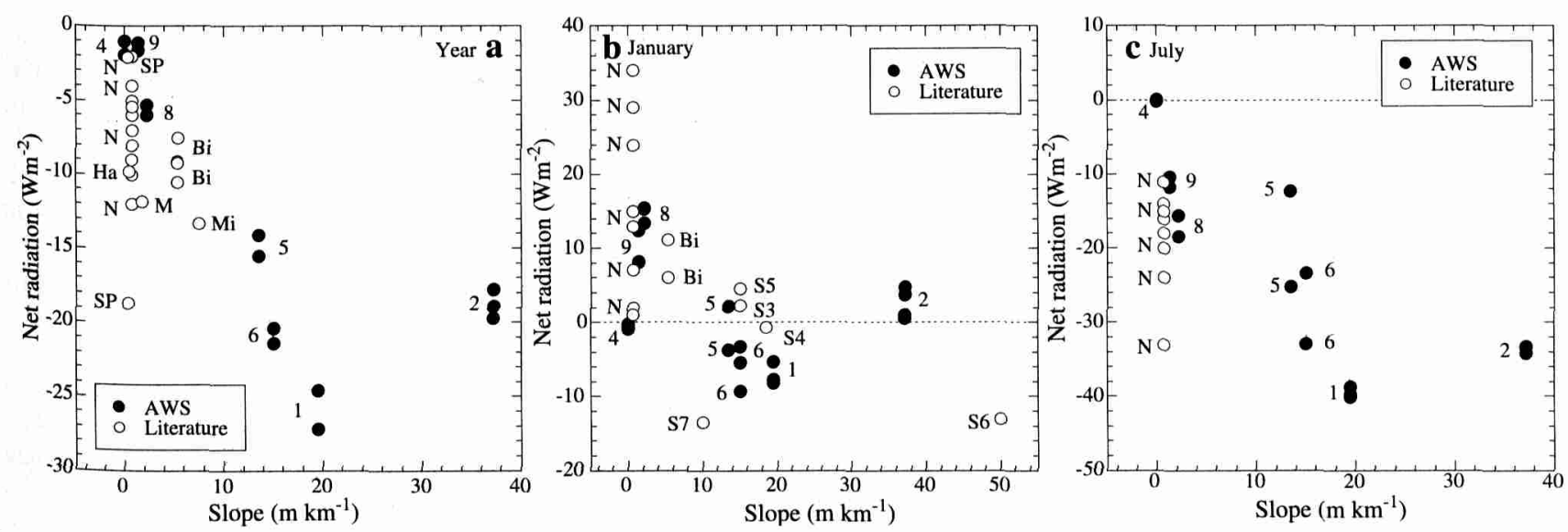

Figure 10. (a) Annual mean, monthly means of (b) January and (c) July net radiative flux as a function of surface slope. Solid circles denote the AWS sites. Open circles denote measurements presented in the literature: N, Neumayer [Schmidt and König-Langlo, 1994; König-Langlo and Herber, 1996]; Ha, Halley; SP, South Pole; M, Maudheim [King and Turner, 1997]; Mi, Mizuho [King and Connelley, 1997]; $\mathrm{Bi}$, Berkner Island [Reijmer et al., 1999]; S5, site 5 [Bintanja and van den Broeke, 1995]; S3, site 3; S4, site 4; S6, site 6; S7, site 7 [Bintanja, 2000].

meteorological conditions and thereby the surface energy balance in DML. The spatial variations in the surface energy balance seem to depend on the strength of the katabatic flow but also on the specific location of each site with respect to distance from the coast, latitude and elevation. Figure 9 shows the annual mean energy balance at the AWS sites as a function of surface slope to illustrate the dependency of the surface energy fluxes on the strength of the katabatic flow.

[31] The apparent dependency of the net shortwave radiation $S$ on slope is caused by an increase in elevation and distance going inland that coincides with the increase in surface slope. Variations in $S$ depend mainly on surface albedo, elevation, latitude and cloud amount. $S$ increases as a function of elevation and distance from the coast. The high $S$ at AWS 8 and 9 can be attributed to a decrease in cloud amount with increasing distance from the coast. In January 1993 the average cloud amount at Neumayer was $\sim 0.66$ [König-Langlo and Herber, 1996], compared to 0.35 near AWS 6 [Bintanja and van den Broeke, 1995].

On the plateau, $S$ depends mainly on latitude.

[32] Net longwave radiation $L$ is negative and decreases With increasing slope. The maximum values in $L$ at the sites with the steepest slope coincides with a maximum in wind speed and potential temperature (Figure 4). The relatively high surface temperatures increase $L \uparrow$, which cause the maximum values in $L$. Because $L$ dominates the radiative balance, $R$ also exhibits a maximum on the edge of the plateau. $R$ is balanced almost completely by a positive $H$, which also exhibits maximum values at the site with the steepest slope. $H$ and $R$ at AWS 2 deviate from this tendency. Both fluxes are smaller than is expected from the local surface slope. This is probably due to the underestimation of the wind speed due to freezing of the sensor and local terrain affecting the strength of the katabatic wind. [33] The dependency of the annual surface energy balance on surface slope and thereby wind speed is determined mainly by the winter balance (Figure 10) because of the hery short and peaked summers on Antarctica. In summer, heating of the surface by solar radiation reduces the sensible heat flux and thereby the cooling of the near surface air, weakening the katabatic flow and increasing the influence of the synoptically forced flow, which governs the annual and diurnal cycle in the energy budget terms. The unusual negative $R$ in summer at the sites in the escarpment region is explained by the southern location of this region in DML compared to other parts of East Antarctica. The large surface slopes result in relatively high wind speeds and sensible heat fluxes at elevations where at other locations the slopes are less steep and the wind speeds less strong. $S$ at these more southern locations is smaller, whereas $L$ is larger due to the higher surface temperatures. This may also explain the difference in diurnal variations in $H$ between the sites on the Antarctic plateau (AWS 2,8 and 9) and in the escarpment region (AWS 1, 5 and 6) (Figure 8), average conditions being stable in the escarpment region and unstable on the plateau. $R$ decreases with increasing slope in the winter.

[34] The relative contribution of $H$ and $L E$ to the heat budget at the various sites also exhibits a clear annual cycle (Figure 11) [Bintanja et al., 1997]. In winter the magnitude of $L E$ is small owing to the low temperatures. The Bowen ratio $(B=H / L E)$ is positive at all stations except AWS 9 and is of the order of 20 . In summer, the fluxes are smaller and the contribution of $L E$ increases resulting in $B$ varying between -5 and 5. $B$ is positive for AWS 8 and 9 and negative for all other stations.

\subsection{Comparison With Other Studies}

[35] The results presented in the previous sections can be compared with heat budgets presented in the literature. Bintanja and van den Broeke [1995] and Bintanja [2000] evaluate the energy balance for the austral summer of 1992-1993 and 1997-1998 for two stations located at exactly the same location as AWS 6. Their results are summarized by Bintanja [2000, Table 7]. He showed that the constant relative humidity assumed by Bintanja and van den Broeke [1995] was too low, which resulted in an exceptionally large $L E$ of $-22.1 \mathrm{~W} \mathrm{~m}^{-2}$. Comparing 

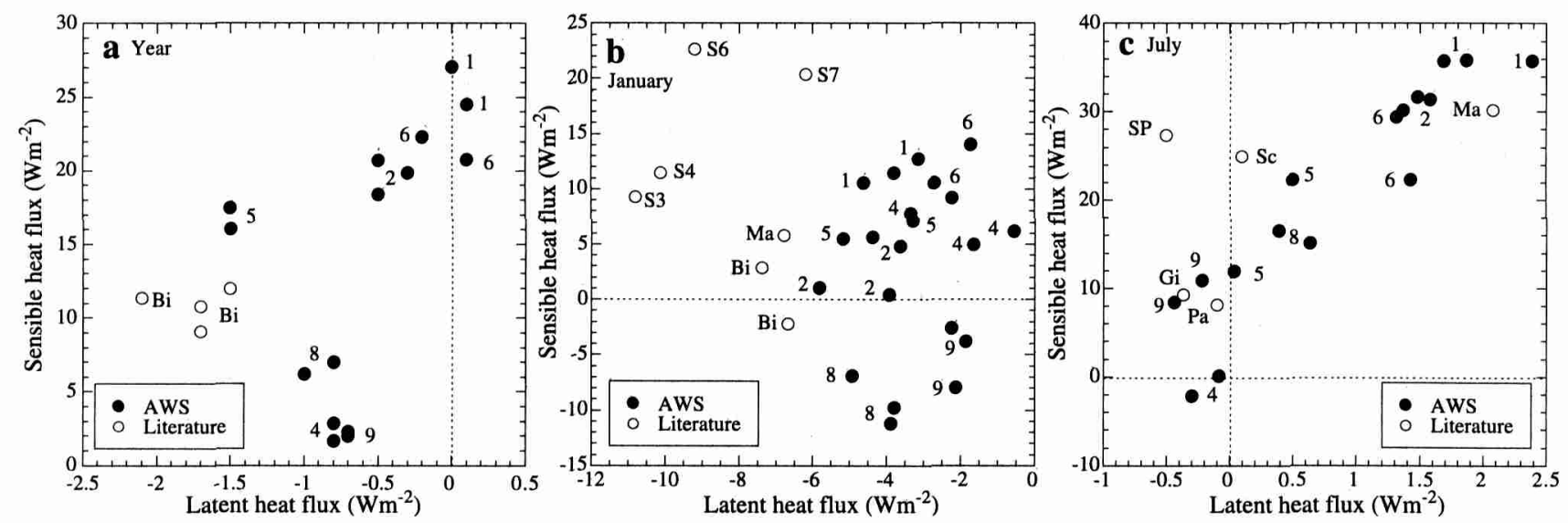

Figure 11. (a) Annual mean, monthly mean of (b) January and (c) July sensible heat flux as a function of the latent heat flux. Solid circles denote the AWS sites. Open circles are measurements presented in the literature: SP, South Pole; Pa, Patrick; Ma, Marilyn; Sc, Schwertfeger; Gi, Gill [Stearns and Weidner, 1993]; Bi, Berkner Island [Reijmer et al., 1999]; S3, site 3; S4, site 4; S6, site 6; S7, site 7 [Bintanja, 2000].

January 1999 and 2000 with the results of Bintanja [2000] shows that our $S$ and $L$ are smaller. This results in a negative $R$ at AWS $6,-5.3$ and $-3.2 \mathrm{~W} \mathrm{~m}^{-2}$, respectively, while the $R$ of Bintanja [2000] is small and positive, i.e., $2.3 \mathrm{~W} \mathrm{~m}^{-2}$. $H$ is of the same order of magnitude, $\sim 10 \mathrm{~W} \mathrm{~m}^{-2}$, and our $L E$ values are smaller, i.e., -2.6 and $-2.0 \mathrm{~W} \mathrm{~m}^{-2}$ compared to $-10.8 \mathrm{~W} \mathrm{~m}^{-2}$. The differences can be partly explained by interannual variability but also by the different methods used to calculate the turbulent fluxes (see also section 2).

[36] The mean diurnal cycle derived at AWS 6 is also in reasonable agreement with results from Bintanja [2000]. $H$ shows near-neutral conditions in daytime averaged over two summers, which agrees with Bintanja [2000]. The diurnal cycle of $L E$ shows positive values at night, whereas Bintanja's [2000] values remain negative all day. Wendler et al. [1988] present the diurnal cycle for a weather station (D-47) in the escarpment region of Adélie Land, East Antarctica. Their results are generally comparable to our results from AWS 1,2 and 6 . However, at D-47, $S$ is higher during daytime owing to the more northerly location of the station compared to the our stations. $H$ is higher during the night, which can be attributed to the higher wind speed at D-47 (annual average $\sim 12.8 \mathrm{~m} \mathrm{~s}^{-1}$ ). In daytime, conditions are unstable at D-47. The sublimation is also larger at D-47 and $L E$ becomes positive during the night.

[37] Almost all estimates of the annual surface heat budgets found in literature are from stations near the coast [King et al., 1996; König-Langlo and Herber, 1996; Reijmer et al., 1999] or the South Pole [Carroll, 1982; King and Turner, 1997]. To examine to what extent the results for DML presented in previous sections can be extrapolated to the entire continent, Figure 10a presents annual mean $R$ as a function of surface slope. The spread in $R$ is considerable, especially at the sites with small slopes (on the plateau and on ice shelves). On plateau stations like South Pole but also Berkner Island, $R$ does not depend on slope but on latitudinal position (not shown). There is a difference in $R$ and in $H+L E$ of an order of magnitude between AWS 8 and 9 and South Pole.

[38] Stations on ice shelves close to the coast are strongly influenced by synoptic weather systems and less by kata- batic flow. Fluxes of $R$ and $H+L E$ at AWS 4 seem to be exceptionally small compared to their values at other coastal stations in this region. For instance, at Halley, Maudheim and Neumayer, annual mean $R$ are $\sim-9.8 \mathrm{~W} \mathrm{~m}^{-2},-11.8 \mathrm{~W}$ $\mathrm{m}^{-2}$ and $-7 \mathrm{~W} \mathrm{~m}^{-2}$ [Schmidt and König-Langlo, 1994; König-Langlo and Herber, 1996; King and Turner, 1997], respectively, compared to $\sim-1.5 \mathrm{~W} \mathrm{~m}^{-2}$ at AWS 4 . This can partly be explained by the underestimation of the surface temperature in the model, which results in $L \uparrow$ that is on average $\sim 1.7 \mathrm{~W} \mathrm{~m}^{-2}$ too low (Table 3 ).

[39] Most of the measurements presented in the literature were carried out in the summer months December and January [Ohata, 1985; Wendler et al., 1988; Bintanja and van den Broeke, 1995; Bintanja, 2000]. Figure 10b presents $R$ as function of slope for January. The figure shows no dependency on slope at all. The spread is fairly large and is partly explained by interannual variability and by the different lengths of the measuring period at the selected stations. For the ice shelf stations the size of the ice shelf and the precise location of the station on the ice shelf, e.g., close to upwind mountains or close to the edge, also plays a role. The summer balance is determined mainly by the net shortwave radiation. The winter balance does exhibit a relation with the surface slope, although the spread is fairly large, especially in the results of Neumayer station.

\section{Concluding Remarks}

[40] The weather stations have provided us with a fairly complete 2 to 3 year data set for seven locations in Dronning Maud Land, Antarctica. Meteorological conditions at these stations are determined mainly by large-scale flow on the ice shelf and by the strength of the katabatic flow at the other sites. The specific humidity is extremely low, while wind speed and potential temperature increase with increasing surface slope.

[41] Surface energy balance calculations at these seven locations indicate that the energy balance in DML is strongly connected to the surface slope and hence to the strength of the katabatic wind. Stronger winds enhance vertical mixing and reduce the surface temperature inver- 
sion, which results in relatively high surface temperatures [Ohata, 1985; Van den Broeke et al., 1999]. The result is a maximum in $H$ and $L \uparrow$, and therefore $L$, at the steepest slopes where the wind speed is strongest. Because $L$ dominates the radiation balance, $R$ also exhibits a maximum at these sites. $S$ depends on distance from the coast, which can probably be attributed to a decrease in cloud amount. $L E$ is fairly small at all sites. However sublimation removes $\sim 0$ to $10 \%$ of the annual accumulation.

[42] The energy balances evaluated here are generally comparable to energy balance estimates for stations at similar locations presented in the literature. Differences can be explained by the different geographical locations of the sites, the different periods during which the budget was evaluated and the different methods used to evaluate the budget.

[43] The energy balance results are presented in terms of the geographical position of the stations, which are categorized in three regions; the ice shelves, the escarpment region and the high Antarctic plateau. These regions have different topography and climate, which results in large differences in the means, long-term variations and diurnal cycles of meteorological variables and energy balance. The ice shelves, especially the smaller ones, are influenced mainly by synoptic weather systems owing to their northerly location near the coast and their flat surface. The energy balance in the escarpment region is determined mainly by the strength of the katabatic flow and therefore strongly depends on surface slope. On the Antarctic plateau the influence of the synoptic forcing is reduced and cloud amounts are low. Owing to the flat surface, katabatic flows are only weakly developed. Here, climate and heat budgets are determined mainly by surface elevation, through temperature, and latitude through shortwave radiation. Note, however, that this holds only for the stations in DML where the escarpment region is located at fairly large distances from the coast. In other parts of Antarctica the steepest slope is closer to the coast. The influence of synoptic forcing will be larger than in DML.

[44] The total amount of surface energy balance data over Antarctica is still limited. Given the vast size of the continent it is not likely that the spatial coverage of this type of measurements will improve considerably in the near future. Our results are useful for verifying climate and weather prediction models currently used to study the Antarctic climate [Genthon and Braun, 1995; King and Turner, 1997; Van Lipzig et al., 1999]. The weather station data constitute an independent data set not used in analyses procedures of climate and weather prediction models. Furthermore, two weather stations are located on the plateau where errors in model elevation are relatively small which facilitates the interpretation of differences between model and observations. In contrast, in the coastal and escarpment regions the errors in model elevation can be substantial, which render model validation problematic.

Martijn Acknowledgments. We thank Richard Bintanja, Henk Snellen, Martijn Thomassen, the members of SWEDARP 1997-1998 expedition, and the Alfred Wegener Institute, Bremerhaven, especially Hans Oerter, invalue members of the Norwegian traverse team of 1996-1997 for their in Dronle help with placing and servicing the Automatic Weather Stations contributing Maud Land. This is EPICA publication 43. This work is a contribution to the "European Project for Ice Coring in Antarctica"
(EPICA), a joint ESF (European Science Foundation)/EC scientific programme, funded by the European Commission under the Environment and Climate Programme (1994-1998) contract ENV4-CT95-0074 and by national contributions from Belgium, Denmark, France, Germany, Italy, the Netherlands, Norway, Sweden, Switzerland and the United Kingdom.

\section{References}

Anderson, P. S., A method for rescaling humidity sensors at temperatures well below freezing, Journal of Atmospheric and Oceanic Technology, II, 1388-1391, 1994.

Andreas, E. L., A theory for the scalar roughness and the scalar transfer coefficients over snow and sea ice, Boundary-Layer Meteorol., 38(1-2), 159-184, 1987.

Bintanja, R., Surface heat budget of Antarctic snow and blue ice: Interpretation of spatial and temporal variability, J. Geophys. Res., 105(D19), 24,387-24,407, 2000.

Bintanja, R., and C. H. Reijmer, Meteorological conditions over Antaretic blue ice areas and their influence on the local surface mass balance, J. Glaciol., 47(156), 37-50, 2001.

Bintanja, R., and M. R. van den Broeke, The surface energy balance of Antarctic snow and blue ice, J. Appl. Meteorol., 34(4), 902-926, 1995.

Bintanja, R., S. Jonsson, and W. H. Knap, The annual cycle of the surface energy balance of Antarctic blue ice, J. Geophys. Res., 102(D2), $1867-$ $1881,1997$.

Carroll, J. J., Long-term means and short-term variability of the surface energy balance components at the South Pole, J. Geophys. Res., 87(C6), 4277-4286, 1982.

Duynkerke, P. G., Radiation fog: A comparison of model simulation with detailed observations, Monthly Weather Review, 119(2), 324-341, 1991.

Fortuin, J. P. F., and J. Oerlemans, Parameterisations of the annual surface temperature and mass balance of Antarctica, Ann. Glaciol., 14, 78-84, 1990.

Genthon, C., and A. Braun, ECMWF analysis and predictions of the surface climate of Greenland and Antaretica, J. Climate, 8, 2324-2332, 1995.

Greuell, W., and T. Konzelman, Numerical modelling of the energy balance and the englacial temperature of the Greenland ice sheet. Calculations for the ETH-camp location (West Greenland, $1155 \mathrm{~m}$ a.s.l.), Global and Planetary Change, 9, 91-114, 1994.

Högström, U., Non-dimensional wind and temperature profiles in the atmospheric surface layer: a re-evaluation, Boundary-Layer Meteorol., 42, 55-78, 1988 .

Holmlund, P., K. Gjerde, N. Gundestrup, M. Hansson, E. Isaksson, L. Karlöf, M. Nyman, R. Pettersson, F. Pinglot, C. H. Reijmer, M. Stenberg, M. Thomassen, R. van de Wal, C. van der Veen, F. Wilhelms, and J.-G. Winther, Spatial gradients in snow layering and $10 \mathrm{~m}$ temperatures at two EPICA-Dronning Maud Land (Antarctica) pre-site-survey drill sites, Ann. Glaciol., 30, 13-19, 2000.

Isaksson, E., and W. Karlén, Spatial and temporal patterns in snow accumulation, western Dronning Maud Land, Antarctica, J. Glaciol., 40(135), $399-409,1994$.

Jonsson, S., Synoptic forcing of wind and temperature in a large cirque 300 $\mathrm{km}$ from the coast of East Antarctica, Antarctic Science, 7(4), 409-420, 1995.

Karlöf, L., J.-G. Winther, E. Isaksson, J. Kohler, J. F. Pinglot, F. Wilhelms, M. Hansson, P. Holmlund, M. Nyman, R. Pettersson, M. Stenberg, M. P. A. Thomassen, C. van der Veen, and R. S. W. van de Wal, A 1500 year record of accumulation at Amundsenisen western Dronning Maud Land, Antarctica, derived from electrical and radioactive measurements on a $120 \mathrm{~m}$ ice core, J. Geophys. Res., 105(D10), 12,471-12,483, 2000.

King, J. C., Longwave atmospheric radiation over Antarctica, Antarctic Science, 8(1), 105-109, 1996.

King, J. C., and W. M. Connolley, Validation of the surface energy balance over the Antarctic ice sheets in the U.K. Meteorological Office Unified Climate Model, J. Climate, 10, 1273-1287, 1997.

King, J. C., and J. Turner, Antarctic Meteorology and Climatology, 409 pp., Cambridge Univ. Press, New York, 1997.

King, J. C., P. S. Anderson, M. C. Smith, and S. D. Mobbs, The surface energy and mass balance at Halley, Antarctica during winter, J. Geophys. Res., 101(D14), 19,119-19,128, 1996.

König-Langlo, G. C., and A. Herber, The meteorological data of the Neumayer station (Antarctica) for 1992, 1993 and 1994, Technical report, $101 \mathrm{pp}$, Alfred Wegener Institute for Polar and Marine Research, Bremerhaven, 1996.

König-Langlo, G. C., J. C. King, and P. Pettre, Climatology of the three coastal Antarctic stations Dumont d'Urville, Neumayer, and Halley, J. Geophys. Res., 103(D9), 10,935-10,946, 1998.

Krinner, G., C. Genthon, Z.-X. Li, and P. Van, Studies of the Antarctic climate with a stretched-grid general circulation model, J. Geophys. Res., 102(D12), 13,731-13,745, 1997 
Oerter, H., F. Wilhelms, F. Jung-Rothenhäusler, F. Göktas, H. Miller, W. Graf, and S. Sommer, Accumulation rates in Dronning Maud Land, Antarctica, as revealed by dielectric-profiling measurements at shallow firn cores, Ann. Glaciol., 30, 27-34, 2000.

Ohata, T., Heat balance at the snow surface in a katabatic wind zone, east Antarctica, Ann. Glaciol., 6, 174-177, 1985.

Parish, T. R., and D. H. Bromwich, The surface windfield over the Antarctic ice sheets, Nature, 328, 51-54, 1987.

Parish, T. R., and D. H. Bromwich, Continental-scale simulation of the Antarctic katabatic wind regime, J. Climate, 4, 135-146, 1991.

Parish, T. R., and D. H. Bromwich, A case study of Antarctic katabatic wind interaction with large-scale forcing, Monthly Weather Review, 126, 199-209, 1998.

Reijmer, C. H., W. Greuell, and J. Oerlemans, The annual cycle of meteorological variables and the surface energy balance on Berkner Island, Antarctica, Ann. Glaciol., 29, 49-54, 1999.

Schmidt, T., and G. C. König-Langlo, Radiation measurements at the German station Neumayer 1982 - 1992, Technical report, 66 pp., Alfred Wegener Institute for Polar and Marine Research, Bremerhaven, 1994.
Stearns, C. R., and G. A. Weidner, Sensible and latent heat flux estimates in Antarctica, in D. H. Bromwich and C. R. Stearns, editors, Antarctic Meteorology and Climatology: Studies on Automatic Weather Stations., vol. 61 of Antarctic Research Series, pp. 109-138, Washington, DC, American Geophysical Union, 1993.

Van den Broeke, M. R., J.-G. Winther, E. Isaksson, J. F. Pinglot, L. Karlöf, T. Eiken, and L. Conrads, Climate variables along a traverse line in Dronning Maud Land, East Antarctica, J. Glaciol., 45(150), 295-302, 1999.

Van Lipzig, N., E. van Meijgaard, and J. Oerlemans, Evaluation of a regional atmospheric model using measurements of surface heat exchange processes from a site in Antarctica, Monthly Weather Review, 127, 11,994-12,011, 1999.

Wendler, G., N. Ishikawa, and Y. Kodama, The heat balance of the icy slope of Adelie Land, Eastern Antarctica, J. Appl. Meteorol., 27, 52-65, 1988.

J. Oerlemans and C. H. Reijmer, Institute for Marine and Atmospheric Research Utrecht, Utrecht University, Princetonplein 5, 3584 CC Utrecht, Netherlands. (j.oerlemans@phys.uu.nl; c.h.reijmer@phys.uu.nl) 